\title{
CORRIGENDUM
}

\section{The impact of maternal characteristics on the moderately premature infant: an antenatal maternal transport clinical prediction rule}

D Dukhovny, S Dukhovny, DM Pursley, GJ Escobar, MC McCormick, WY Mao and JAF Zupancic

Journal of Perinatology (2013) 33, 413; doi:10.1038/jp.2013.29 Correction to: Journal of Perinatology (2012) 32, 532-538;
doi:10.1038/jp.2011.155

Following the publication of this article, the authors found an error in the description of the Moderately Premature Infant Project (MPIP) cohort. The cohort was described as being restricted to infants whose birth weight was $1500-2499 \mathrm{~g}$, but, in fact, there were no restrictions and the birth weights ranged from 591 to $3540 \mathrm{~g}$.

The error appears in two places: in the Study Design section of the abstract and in the Methods section under 'Study Design and Patient Population' (page 533, left column).
The error has no impact on the authors' results or conclusionsbirth weight was intentionally not used in any of the models as a predictor variable for the need for maternal transfer because it is so difficult to predict using estimated fetal weight, with a significant margin of error. Furthermore, the mean birth weight and standard deviation in Table 1 accurately reflect the full range of birth weights. 